\title{
Pontes, Prismas e Percursos: a escrita da história intelectual argentina pós giro linguístico à luz das análises de Facundo
}

\author{
Bridges, Prismas and Paths: the writing of argentine intellectual \\ history after linguistic turn in Facundo's analyzes
}

\section{Fabíula Sevilha}

\section{RESUMO}

As décadas de 1960 e 1970, com o chamado giro linguístico e a crise de paradigmas das ciências sociais, trouxeram consigo novas abordagens, métodose desafios ao campo historiográfico. A história dos intelectuais passou a se interessar não só pelas trajetórias, mas também por uma história propriamente intelectual, isto é, pela dinâmica plural e multidisciplinar de construção das ideias; e pelas relações do autor com a obra, com o seu tempo e com outras obras. Neste artigo, analisamos como essas questões foram mobilizadas por Carlos Altamirano e Oscar Terán no exame de Facundo: civilización y barbarie (1845), de Domingo Faustino Sarmiento, por meio da relação dialética entre texto, contexto e conectores. A hipótese central é de que as "categorias mediadoras" foram operacionais no programa de história intelectual argentina. Tal recurso permitiu evidenciar o discurso histórico como prática social, direcionamento caro ao grupo Prismas e ao contexto pós-giro linguístico.

\section{PALAVRAS-CHAVE}

História intelectual; História da historiografia; Domingo Faustino Sarmiento.

\section{ABSTRACT}

In the decades of 1960 and 1970, the so-called linguistic turn and the crisis of the social sciences paradigms brought along new approaches, methods and challenges into the historiographic field. The history of the intellectuals started to become interested in not only the trajectories per se, but also in a properly intellectual history, that is, the plural, multidisciplinary dynamics of building ideas, the relations between the author and the piece, their time and other works. In this paper, we analyzed how these issues were moved by Carlos Altamirano and Oscar Terán by looking into Facundo: civilización y barbárie (1845), by Domingo Faustino Sarmiento, through the dialectical relationship among text, context and connectors. Our main hypothesis is that the connectors were operational in the argentine intellectual history program. This tool made it possible to highlight the historical discourse as a social practice, aimed by the Prismas group and the after linguistic turn context.

\section{KEYWORDS}

Intellectual history; History of historiography; Domingo Faustino Sarmiento 
As décadas de 1960 e 1970, com o chamado giro linguístico e a crise dos paradigmas das ciências sociais, trouxeram consigo novas abordagens, novos métodos e desafios ao campo historiográfico. Nesse contexto, a simples busca de uma correlação entre ideias e biografias de nomes de relevo não mais atendia aos anseios da história intelectual. Habilitada com nova roupagem - no cruzamento da clássica história das ideias com a filosofia da história, a história das mentalidades e a história cultural (SIRINELLI 2003) - ela passou a se interessar não só pelas trajetórias. A uma história dos intelectuais somouse uma história propriamente intelectual, isto é, atenta às formas de transmissão da informação (BURKE 2007, p. 162); à relação do autor com a obra, do autor com o seu tempo e do autor com outras obras. Em suma, a uma história cultural das ideias (CHARTIER 2002, p. 30).

Para Heloisa Pontes (1997), é possível sistematizar as bases da história intelectual recente em "internalista" e "externalista". A primeira, tributária da linguística estrutural, da semiologia e da história da arte, tem como enfoque a análise da composição interna de obras e produtos culturais, similar à abordagem metodológica estruturalista de Claude Lévi-Strauss. A segunda, que tem entre seus adeptos Norbert Elias e Pierre Bourdieu, interessa-se pelas condições sociais da produção cultural e intelectual das ideias e das obras, o que engloba desde o perfil dos produtores até as representações, ideologias, práticas sociais e o mapeamento do campo no qual a produção está inserida. Na raiz da divisão entre essas duas abordagens, Quentin Skinner (1969) identificou "ortodoxias" - o "textualismo" e o "contextualismo sociológico" - que compartilhariam da mesma inadequação: a insuficiência para a correta compreensão de qualquer obra. No lugar, propunha um contextualismo linguístico, atento à intencionalidade do autor no contexto imediato da produção do texto, abordagem que foi duramente criticada na década de 1980.

A partir de então, ainda que seja possível identificar clivagens, a perspectiva integrada da diacronia com a sincronia, 
tão presente em análises de autores da história dos conceitos, como Reinhart Koselleck (2006), ganhou espaço entre os estudiosos da área. Para Carl Schorske (1998), a história intelectual deve ter em mente duas linhas de força: a vertical, diacrônica, que relê um texto ou um sistema de pensamento à luz de seus precedentes e sob um mesmo ramo da atividade cultural; e a horizontal, sincrônica, que possibilita ao historiador estabelecer uma relação entre o objeto intelectual e o que foi feito em outras áreas no mesmo período.

Os defensores de renome, no entanto, não isentam a proposta de críticas. Para François Dosse (2003), enxergar como necessário o entrelaçamento da lógica exógena com a endógena é naturalizálas, criar uma falsa alternativa. Há, entre ambas, um espaço que denomina como "indeterminação epistemológica", próprio da história intelectual, e cumpre ao historiador encontrar categorias que sirvam de mediação entre uma dimensão e outra. Alguns caminhos para o autor seriam a utilização dos dois conectores elencados por Jean-François Sirinelli, isto é, o de "geração" e o de "sociabilidade intelectual"; bem como a noção de "apropriação" de Roger Chartier; e a distinção fundamental que Michel de Certeau faz entre escrita e leitura.

Em verdade, há inúmeros conectores possíveis e não excludentes. Pode-se, por exemplo, trabalhar em uma mesma obra a presença das ideias de uma geração, as estratégias narrativas e argumentativas do autor, para tentar controlar a recepção de sua obra, e as leituras plurais que se fizeram dela de acordo com o contexto. Acreditamos que isso implica considerar uma relação dialética entre texto, contexto e conectores, e mesmo lançar mão da análise paratextual. Neste artigo, examinamos como esses fatores foram mobilizados por Oscar Terán e Carlos Altamirano em duas análises de Facundo: civilización y barbarie, do intelectual liberal argentino Domingo Faustino Sarmiento.

Esse livro foi publicado em 1845, no Chile, enquanto Sarmiento estava no exílio, em razão da oposição declarada a Juan Manuel de Rosas, governador de Buenos Aires. O 
personagem principal em torno do qual o enredo foi construído é Juan Facundo Quiroga, um caudilho de La Rioja, a um só tempo adversário e correligionário de Rosas. Muito embora o desfecho do livro atribua a Rosas a autoria da emboscada que matou Quiroga em 1835, o objetivo de Sarmiento vai além de uma simples oposição ao regime vigente. Uma das grandes contribuições de Facundo é trazer em sua narrativa uma configuração sociocultural que expressa a "eterna luta entre civilização e barbárie", que está na gênese da formação nacional argentina e do pensamento latino-americano oitocentista (WASSERMAN 2008).

As abordagens de Altamirano (2005) e Terán (2007) nos permitem não apenas conhecer melhor essa obra fundacional, mas problematizar as metodologias de trabalho da história intelectual, conforme propostas pelo grupo Prismas, no contexto pós giro linguístico. Para tanto, dividimos o artigo em três partes. A primeira esmiúça os métodos, metodologias e problemáticas presentes no trabalho de Terán. A segunda traz Altamirano para o debate e contraponto. E a terceira, por fim, pontua algumas zonas de contato como forma de identificar problemas e desafios que perpassam as abordagens e são comuns à historiografia intelectual.

\section{Cercando a obra: a história do livro}

Oscar Terán, filósofo e historiador argentino, elabora o que poderíamos chamar de biografia de uma obra, uma tentativa mais focada no padrão geral de produção do que propriamente de consumo (DARNTON 2008). Por acreditar que nem todo o arcabouço necessário para compreender Facundo está no texto, Terán atribuiu papel fundamental ao contexto material. Seu livro Para leer el Facundo (2007) inicia-se com a contextualização da obra de Sarmiento ou, em outras palavras, com o mapeamento de seu "lugar social" (CERTEAU 2008). Politicamente, o marco foi a ascensão de Juan Manuel de Rosas ao poder, em 1829, e o conflito entre unitaristas e federalistas. Defensor do projeto político desse último grupo, Rosas estabeleceu uma série de 
pactos com governadores e governou "com mão de ferro" a Argentina, de forma intervalada, até 1852 (PRADO 2004, p. 155).

Culturalmente, Terán identifica um marco estético. Ainda que tardiamente, Sarmiento entrou em contato com a chamada Geração de 37, grupo formado no Salão Literário de Buenos Aires. Influenciados pelo Romantismo francês, essa nova geração de intelectuais se colocava como responsável pelo desenvolvimento do Estado e pela transformação moral da sociedade (GOLDMAN; PASINO 2008, p. 110). O grupo se opunha a Rosas por ver nele a "encarnação do absolutismo, da arbitrariedade e da barbárie". Dada a repressão ditatorial rosista, esse grupo se exilou no Chile e no Uruguai, de onde produziu escritos de oposição ao governador e de defesa de um Estado guiado "pelas luzes da razão". Sarmiento somente tomou contato com os escritos da Geração em 1838, mas eles se tornaram fundamentais em sua formação (TERÁN 2007; PRADO 2004, p. 155).

A fim de delinear as nuances da recepção seletiva que a Geração de 37 fez da tradição intelectual e literária francesa, Terán faz uma breve descrição do Romantismo, mais precisamente dos contornos que assumiu na Argentina e como se desdobrou em Sarmiento. A racionalidade anterior da Ilustração foi o contraste central para os românticos, adeptos do fluir dos sentimentos e da imaginação. Um dos principais expoentes da vertente argentina foi Esteban Echeverría, de quem a Geração de 37 foi tributária. Quando de seu retorno da França em 1830, Echeverría trouxe consigo as novidades do Romantismo: a exaltação do grande homem como herói e de um passado épico; o fascínio pela natureza sublime e desafiadora; e a valorização do original de cada cultura, dos usos e costumes que identificam uma nação. Recompondo esta "topografia de interesses" (CERTEAU 2008) a fim de entendermos melhor o enredo arquitetado por Sarmiento, Terán mostra que os temas são lugar comum em Facundo. ${ }^{1}$ 1 - Em que pese esta
constatação, é pre-
ciso abrir um parên-
tese. Como nos aler-
ta Fábio Wasserman
(2008), as preocu-
pações de Sarmiento
em Facundo não se
enquadram no que
seria a tessitura de
uma história nacional
como pregavam os
românticos france-
ses. Devido à própria
singularidade que o
Romantismo assumiu
na região do Rio da
Prata, havia uma de--
marcada preocupação
com o presente. Na-
ção e nacionalidade
eram interpretadas
como projetos mais
dependentes de um
futuro do que de um
passado histórico.

Ciente de que a dinâmica de produção de uma obra não 
se restringe ao contexto material e à recepção das ideias que a embasaram, Terán estreita o cerco. Um pouco por conta da própria característica de Facundo, um pouco pelas preocupações que caracterizam o grupo Prismas, de que trataremos adiante, há todo um cuidado de análise sobre o gênero do livro. Segundo o autor, cada finalidade guarda um tipo de escrita e isso é ainda mais contundente em Sarmiento. Facundo foi publicado na forma de diversos folhetins, durante o exílio de Sarmiento no Chile, como defesa aos ataques de um enviado de Rosas. Estaria aí a razão do tom político e panegírico, a procura por construir uma versão verossímil do relato, a busca pelo convencimento, bem como a dificuldade de alocar o texto em um único gênero. Para Terán, essa diversidade é antes de tudo parte da própria estratégia argumentativa de Sarmiento e da finalidade que atribuiu ao seu texto. O objetivo sarmientiano é revelar o "enigma argentino", entender o porquê da Revolução de Maio, libertária em essência, ter culminado no despotismo rosista. Para atingir tal propósito e conferir estatuto de verdade ao que diz, Sarmiento lançou mão de argumentações científicas, analógicas, simbólicas, religiosas e literárias. Não à toa, explica Terán, elementos próprios ao ensaio, novela e biografia histórica são identificáveis no livro.

Em um movimento que nos leva, enfim, a adentrar Facundo, Terán elabora quatro perguntas: quem fala? O que diz? Como diz? Para quem? À procura de tais respostas, o autor vai ao encontro da proposta de Antoine Compagnon (1996, p. 71), para quem as portas de entrada de um livro são o título e o subtítulo, cuja função primeira é a evocação "de todo o texto por um signo que o compreende". Terán parte, então, do título para analisar a construção da figura de Quiroga e do subtítulo para compreender como dois conceitos centrais aparecem na obra. A análise, acertadamente, esmiúça e mostra o lugar do conceito na construção narrativa. Como nos lembra Koselleck (2006, p. 101), é no nível linguístico que se apreendem as polêmicas do presente, entrelaçadas com elementos de longa duração, e os componentes acionados para o estabelecimento de um programa de futuro. Nesse sentido, Terán conclui que o 
fato de "civilização" e "barbárie" aparecerem ora juntas, como no subtítulo, ora separadas, é um indicativo de que a Argentina vista por Sarmiento é o lugar do hibridismo, do encontro, da interpenetração, da fricção.

Com efeito, Rosas ilustrava a mudança ocasionada pela politização da população rural argentina. Como representante político desse "perigoso setor popular que os unitários cometeram o erro de ignorar", o seu projeto era elevar ao máximo as tensões entre diferentes facções até o triunfo das massas e o estabelecimento da paz nacional. A morte de Quiroga teria facilitado a transformação autoritária do regime provincial (HALPERIN DONGHI 1993, p. 302). Portanto, conclui Terán, Quiroga não é apenas um caudilho, mas um modelo que condensa a barbárie como resultado de causas estruturais e conjunturais profundas. A civilização argentina, segundo o caminho traçado por Sarmiento, dependeria da superação desses limites.

Conquanto Terán não tenha citado, é possível identificar na análise o esquema proposto por Gérard Genette (1997) de divisão de título, título secundário e subtítulo, cabendo a cada um deles funções próprias. As do título podem ser divididas em três: designar o tema, indicar o objeto a ser tratado e seduzir o público. Há ainda títulos formais, genéricos e temáticos. Quando os títulos são literais - eles podem ser metafóricos ou irônicos -, apontam diretamente para o tema ou o objeto central do livro. As indicações de gênero - história, romance, novela - são geralmente seguidas do título. No caso do livro de Sarmiento, temos Facundo - Civilización y Barbarie - Vida de Juan Facundo Quiroga. Podemos pontuar que o tema é exposto literalmente, seguido do problema e do que seria o seu gênero. Nesse último quesito, a análise teraniana nos leva a concluir que Facundo foi vítima da armadilha sinalizada por Genette, qual seja, a de um título que mascara um gênero inovador, que em Sarmiento está precisamente no "acúmulo de tipos argumentativos", para utilizar os termos de Terán.

Se o título dá as boas-vindas, a epígrafe é um dos pilares 
sobre os quais o texto está assentado (COMPAGNON 1996). Dado o seu caráter de citação, ela ressoa na obra e Terán parece ser muito sensível a essa percepção. Segundo ele, Sarmiento traduz a epígrafe "Nós não matamos as ideias" do francês para o espanhol como "Aos homens se degüella; às ideias, não". A substituição da palavra "matam" por degüella, do léxico gaucho, explica, é um ato de nacionalização, de tradução da língua civilizada para os termos locais, somente assim compreensível aos "bárbaros". Com tal análise, Terán responde a algumas perguntas centrais: quem fala e assume o papel de epigrafista é Sarmiento, o civilizado. O narrador da história é encarnado pela mesma pessoa, uma figura dotada de um argumento de autoridade "civilizacional". Este, como mostra Terán, é reforçado pela sua vinculação institucional a qual não aparecia na publicação em folhetim, mas que está presente no livro, logo abaixo da epígrafe. A credibilidade do testemunho, garantida pela autoria e filiação institucional (GENETTE 1997, p. 41), algo característico do Romantismo, foi intencionalmente perseguida por Sarmiento.

Da epígrafe, Terán nos conduz à Introdução e para cada um dos capítulos, incluindo os dois que Sarmiento manteve e excluiu de algumas edições, conforme a conjuntura política da época. No caminho, Terán chega a conclusões que valem ser mencionadas. A primeira diz respeito ao Pampa argentino como vazio de civilização, um local que produziria tipos, motivo pelo qual Sarmiento descreve o cenário antes de apresentarnos a biografia de Quiroga. A segunda - não explicitada, mas perceptível nas entrelinhas -, é que a dicotomia cidade/ campo ou civilização/barbárie não está apenas em Facundo; ela está no povo argentino e, portanto, no próprio narrador. Nas palavras de Terán (2007, p. 75), a alma romântica de Sarmiento simpatiza com Quiroga, ao passo que a sua alma "moderna" e "civilizada" é atraída por Rosas. Modernidade e civilização até certo ponto, pois o próprio Sarmiento, nascido na cidade de San Juan, só conheceu Buenos Aires após o exílio e a publicação de Facundo. 
Feita a imersão profunda, o movimento final de Terán é deixar novamente o interior do livro para responder à pergunta: como leram Facundo? Era presumível uma análise mais densa e aprofundada, o que não se concretiza. A preocupação de Terán é com o leitor virtual, aquele que o escritor supõe. Ainda que aponte que, para esses casos, o historiador deve estar atento aos elementos do léxico, as marcas, estilos, citações, pactos de leitura e comunidade de sentido, Terán recorre a testemunhos e comentários de época. A conclusão a que o autor chega é a de que a recepção positiva de Facundo veio do exterior, de uma crítica consagratória de autoria de Charles de Mazade, publicada pela Revue des Deux Mondes. Para Beired (2003), o próprio Sarmiento percebeu intuitivamente que as suas ideias não se restringiam às fronteiras argentinas, e que Facundo ia ao encontro dos anseios de uma legião de leitores latino-americanos preocupados em explicar os "enigmas políticos" de seus respectivos países. Essa afirmação nos leva ao percurso contrário de Terán: da obra ao autor.

\section{Cercando o autor: o escritor como "momento histórico"}

Cercar o autor é, precisamente, o caminho escolhido pelo historiadoresociólogoargentinoCarlosAltamirano. EmIntroducción al Facundo (2005), a perspectiva da trajetória intelectual ainda é forte. Contudo, a nosso ver, Altamirano consegue ampliar as perspectivas de análise, ao entender Sarmiento como "momento histórico" (FOUCAULT 1992) e, sobretudo, como um historiador, sujeito aos procedimentos de uma operação historiográfica. $O$ percurso definido atende à preocupação de examinar a escrita da história de Facundo (e da nação argentina) a partir das relações entre o lugar, os procedimentos de análise e o texto (CERTEAU 2008). Assim, o texto é dividido em quatro partes, e a análise iniciada pela vida de Sarmiento. Vemos a sua infância de penúria e o quanto lamentava que isso o tivesse impedido de estudar; a experiência nas vicissitudes das lutas civis argentinas como fornecedoras dos objetos e temas do seu projeto civilizador; e o papel fundamental do exílio na construção da noção sarmientiana de cultura como geradora de costumes ordenadores de impulsos 
e paixões.

Trata-se, de um lado, de montar o "espaço de experiência" para a compreensão do "horizonte de expectativa", de outro, de precisar a "função do autor", de indagar de onde o texto vem, quem o escreveu, quando ou em quais circunstâncias, a partir de qual projeto? (CERTEAU 2008; KOSELLECK 2006; FOUCAULT 1992). Tal como Terán, Altamirano coloca Sarmiento como um herdeiro da Ilustração rivadaviana. As ideias do Romantismo francês lhe foram apresentadas por um jovem ilustrado, Manuel Quiroga Rosas, com quem fez um curso. Dessas leituras extraiu a concepção de história como um vasto drama, em que cada segmento da vida social compunha as partes de um todo. Homem de ação política, Sarmiento encontrou na imprensa a vocação como escritor e assumiu cargos públicos, inclusive no Chile durante o exílio. Na breve descrição que faz da carreira de Sarmiento, Altamirano conclui que o projeto civilizador sarmientiano se transformou em seu programa de governo à frente da Presidência da Argentina (1868-1874), uma vez que suas políticas no terreno das comunicações e da educação conferiram ao país uma feição moderna.

Na segunda parte do texto, Altamirano, de certa maneira, relativiza e desmistifica o domínio de Sarmiento sobre a escrita e recepção da obra, tangenciando um ponto essencial do círculo hermenêutico ricoeuriano - a Mimese 3, a partir da qual o leitor se torna também um coautor da obra, o responsável pela refiguração da intriga que Ihe foi apresentada (RICOEUR 1994, p. 118). Altamirano discute as dificuldades de definir Facundo em termos de gênero e estilo, mas, ao contrário de Terán, não atribui isso a uma estratégia argumentativa, e sim ao fato de que a obra é de tal maneira fundacional que, após a morte de Sarmiento, ganhou vida independente. Não obstante ser alçado à condição de clássico em dois campos da cultura argentina, a do pensamento e da literatura, o livro tornou-se objeto das mais diferentes leituras da história intelectual argentina.

$\mathrm{Na}$ terceira parte de Introducción, somos levados aos meandros da Mimese 2, isto é, à configuração textual da intriga sarmientiana. Altamirano utiliza as palavras do próprio Sarmiento 
para adentrar a discussão sobre o livro em si e identificar como estratégia narrativa o movimento entre passado e presente. É pelo desvendar do solo, dos costumes, das tradições populares, bem como da vida de Quiroga, que Sarmiento busca revelar o enigma argentino. Pode-se dizer, muito embora o próprio crítico não faça, que esse vaivém atualiza constantemente o enigma argentino, ao mesmo tempo em que o localiza em uma tradição (RICOEUR 1994). Na concepção de Altamirano, a estratégia de Sarmiento ultrapassa o convencimento dos pares. Ele reivindica, e talvez esteja aí a força de seu discurso, o lugar dos hispanoamericanos no debate sobre a luta de seus povos, e se coloca como pessoa autorizada a falar disso, transformando o que vê como desvantagem (ser um escritor argentino) em vantagem.

A quarta e última parte de Introducción dedica-se à divisão do livro. Segundo Altamirano, a divisão é feita conforme a visão romântica de história sarmientiana, que vê entre o personagem e o meio uma unidade orgânica. Posto que Sarmiento considera Quiroga não só um caudilho, mas uma manifestação da vida argentina, Facundo é dividido com base na explicação do meio físico e histórico em que se desenha a vida de seu personagem. A campaña argentina aparece como lugar de primitividade, onde a figura do gaucho foi moldada. A dicotomia cidade $\mathrm{x}$ campaña dá a tônica do discurso. Altamirano explica que ambas são produto da ação conjugada do meio físico americano com a colonização espanhola. Explicitaríamos essa questão ainda mais: não estariam, portanto, simbolizando a própria tensão existente entre colonos e colonizados, estopim da Revolução de Maio? Para Altamirano, é na formulação desse esquema das duas sociedades que Sarmiento guarda a chave para desvendar o segredo das convulsões argentinas: a dupla luta ativada pelo processo revolucionário, ao colocar em contato a civilização e a barbárie.

À descrição do cenário segue-se o relato da vida de Quiroga e é nesse momento que Altamirano realiza mais detidamente a sua análise metodológica. Sarmiento nos leva a crer que a composição do meio criou as condições para a trajetória do caudilho, a qual permite agregar os elementos dispersos e descontínuos de uma 
história coletiva, a do povo argentino. Assim, dá o tom sarmientiano ao Romantismo francês que o teria inspirado. A preocupação não é a busca na cultura rural dos elementos da cultura de um povo autóctone, original. $\mathrm{O}$ que o autor de Facundo valoriza, a partir da ideia de civilização, não são hábitos e instituições, mas a associação urbana no espaço público que a cidade engendra e que a campaña impossibilita. O Pampa, em sua imensidão, isolaria as pessoas e, ao contrário da cidade, não permitiria a interação regular entre os homens, que é moderadora dos impulsos do homem e geradora do sentido e do interesse pela noção de "público".

Merece destaque em Altamirano a análise de um conceito de Facundo que foge do lugar comum "civilização" e "barbárie", ainda que ligado a eles, que é a ideia de despotismo. Para Altamirano, essa "pieza central de la doctrina del caudillismo bárbaro" foi buscada na associação que Montesquieu (16691755) faz entre meio e a configuração dos regimes despóticos. Sarmiento transpõe a concepção para o caso argentino. O Pampa aparece (tal qual a planície asiática montesquiana) como o lócus de engendramento da barbárie e do domínio dos caudilhos.

No exame dos recursos narrativos sarmientianos, Altamirano afirma que o autor de Facundo alterna a inteligibilidade da verdade com a eloquência da oratória e a sensibilidade. Utilizando-se de uma metáfora clássica do teatro, Sarmiento associa cena, personagem e ações com representação, drama e espetáculo. O sentido mais acionado é o da visão, o único capaz de dar conta das sutilezas da verdade. Altamirano acredita que o discurso vai nessa direção, porque sensibilizar é fazer ver; e tornar visível é instruir. Aqui se torna evidente o seu projeto civilizador pelas vias da educação, posteriormente materializado quando se tornou presidente da Argentina. Sarmiento já estaria preocupado com a recepção do texto desde a concepção da obra. Ao leitor, explica Altamirano, estariam destinadas as estratégias de doutrinamento, digressão e polêmica. A morte de Quiroga era também o recomeço que Sarmiento esperava para a Argentina: uma nação una e indivisa, livre da barbárie 
dos caudilhos e de Rosas. Como uma tragédia que "resolve poeticamente as aporias da alma" (REIS 2012, p. 153), a narrativa histórica sarmientiana teria a função de trazer o povo argentino às luzes interrompidas pelo governo rosista e tornar o seu "enigma" inteligível.

\section{Transpondo a cerca: por/para um programa de história intelectual latino-americana}

As análises de Oscar Terán e Carlos Altamirano são dois exemplos de abordagens que desnaturalizam a oposição entre internalismo e externalismo. Nossa hipótese é de que os autores adotam, de maneira amplificada, a estratégia postulada por François Dosse (2003): os conectores. Os contextos endógenos e exógenos das obras são apenas o ponto de partida. Não há entre eles uma ligação direta e inexorável, mas eles se tocam a todo momento. O que permite vê-los de maneira dialética são os mediadores: a trajetória, a questão geracional, os paratextos, a recepção, entre outros. Não obstante elucidar aspectos de uma obra essencial para o pensamento latino-americano, essas questões são fundamentais para a problematização da própria escrita da história intelectual, razão de nosso interesse.

De todos os conectores elencados anteriormente, o da trajetória talvez seja o que mais desperta desconfiança entre os pesquisadores da área. Jean-François Sirinelli (2003, p. 247) é enfático, ao afirmar que os itinerários possuem problemas tão sérios de constituição quanto de interpretação. O historiador deve estar consciente das armadilhas, bem como evitar generalizações e aproximações duvidosas, pois muitas vezes a extrema diversidade impede que se chegue a explicações globalizantes. É preciso ter em mente uma característica para a qual Roger Chartier (2012, p. 7) nos chama a atenção: os livros são sempre resultado de múltiplas operações e intervenções.

Carlos Altamirano tem essa precaução. As fontes para traçar um esboço biográfico do autor de Facundo são as memórias do próprio Sarmiento. Entretanto, não há uma 
apreensão ingênua; as informações são submetidas a um filtro por considerá-las excessivamente ideologizadas. Nos apontamentos de Altamirano, o que poderia ser uma fragilidade acaba convertido em ferramenta para problematizar a própria construção da vida e da narrativa sarmientiana. Dessa maneira, Altamirano indica uma perspectiva que tende a ser produtiva aos historiadores intelectuais.

É também Sirinelli (2003, p. 254) quem nos alerta sobre os perigos da abordagem geracional, já enunciados pelos pais fundadores dos Annales. Conquanto seja uma ferramenta sedutora, Sirinelli explica que a questão geracional é duplamente perigosa: pode levar à falsa esperança de "chave-mestra" para entender os intelectuais e suas relações com a política e enunciar truísmos. Os trabalhos aqui analisados mais uma vez escapam a essa visão reducionista. A noção de geração é antes um suporte na tentativa de adensamento analítico de Facundo.

Terán acredita que foi a Geração de 37 quem elaborou o topos do pensamento hispano-americano do período e investe nesse ponto, para entender como Sarmiento formulou suas ideias ora em aproximação ora em oposição aos autores desse grupo. Da mesma forma Altamirano, que enxerga na obra tanto uma saudação de reconhecimento à Geração de 37 quanto as possibilidades de julgamento de quem a considera um capítulo superado - estratégia de aceitação e legitimação, talvez. O contrapeso aos riscos de um determinismo geracional emerge com a inserção de outros dados do "lugar social", pinçados da biografia de Sarmiento, do meio físico e do cenário político. Estes são fundamentais para compreendermos a "linguagem do fazer", a "tradição cultural", o sistema simbólico a partir do qual a intriga se constrói e ganha legibilidade para a ação (RICOEUR 1994, p. 91-93). Isso pressupõe lembrar que a significação de uma obra não só depende de regras de interpretação como ela própria tem uma mobilidade instável e variável no tempo (CHARTIER 2012).

Portanto, a zona de intersecção entre diacronia e sincronia é complexa. A fim de enfrentar o desafio de desvendar as suas 
idiossincrasias, os historiadores incorporaram dos estudos literários e linguísticos ferramentas analíticas importantes. Conforme Gérard Genette (1997), uma obra pode ser dividida em três partes: o peritexto, que é o próprio livro (ou artigo); o epitexto, relativo ao que está fora dele; e o paratexto, correspondente à fronteira entre o interior e o exterior do livro, ao espaço de influência sobre os grupos heterogêneos de práticas e discursos (o público). A questão paratextual carrega uma historicidade perceptível nas suas características espaciais, temporais, substanciais, pragmáticas e funcionais, e defini-las implica responder "onde, quando, como, quem, para quem e por quê?". Ora, não são essas as questões que Terán e Altamirano se colocam? Há, nos dois, um esforço de entender a historicidade do autor, da obra e da leitura (CHARTIER 2012; FOUCAULT 1992). Cada qual a sua maneira, Terán e Altamirano esforçaram-se por cumprir os seis níveis de análise que, segundo Dominick Lacapra (1983, p. 254-269), cabem ao historiador da história intelectual: as relações entre as intenções do autor e o texto; a vida do autor e texto; a sociedade e o texto; a cultura e o texto; o texto e outros textos (da mesma autoria e de autorias diferentes); e o modo do discurso e o texto.

As perguntas "quem diz, quando, onde, como e por quê?", muito embora sejam comuns, têm funções diferentes nas duas análises. Para Terán, importa pensar como Facundo ajuda a compreender Sarmiento e a sociedade argentina/latinoamericana, ao passo que, para Altamirano, o ponto central é a função do autor na representação de uma narrativa, de um contexto. Em comum, a ambos interessa o produto final, o discurso histórico como uma prática social (CERTEAU 2008). Da epígrafe à divisão do livro, tudo foi meticulosamente pensado, revelando muito de Sarmiento, da sociedade em que ele se fez e do que pretendia com sua obra, isto é, qual a finalidade de seu texto como fator de ação política. Terán e Altamirano foram unânimes em afirmar que Sarmiento tinha uma preocupação com o leitor já nos primeiros momentos da escrita, o que nos coloca diante de um importante problema para a história intelectual: a recepção. 
Em defesa de sua hipótese, Terán diferencia o leitor imaginário, que o escritor supõe; e o leitor real, o que efetivamente lê a obra. Sua definição diverge da de Antoine Compagnon (1996, p. 90-91), para quem, alinhado a uma ideia freudiana, há uma diferença entre o autor e o sujeito da enunciação. O primeiro é, na fantasia da escrita, o leitor imaginário, "o eu ideal onde esse se satisfaz ou o ideal do eu onde ele deseja se satisfazer". A escrita é a atualização do projeto, a reescrita da fantasia que produz "ao mesmo tempo o texto e o sujeito de sua enunciação". À criatura imaginária (leitor, autor, ideal do eu) resta "sancionar a criação".

Ao considerar que a única liberdade que um texto concede ao leitor é o de acomodação, a interpretação de Compagnon (1996) oscila entre a liberdade criativa do leitor e o protagonismo do autor, e suscita a pergunta feita por Roger Chartier (2012, p. 18): afinal, quem domina o sentido do texto? Há, na topografia paratextual, "falhas geológicas" provenientes da questão de que o autor não detém o controle sobre a recepção e de que não há uma relação linear entre as intenções dos produtores intelectuais e de seus produtos. Em razão disso, a resposta está no entendimento do peritexto como um centro de relações variadas. No âmbito da proposta ricoeuriana, a peça central é o leitor, é ele quem articula prefiguração, configuração e refiguração do tempo; que termina a obra, que dá sentido às palavras recebidas do autor (RICOEUR 1994; REIS 2012, p. 159). Nesse sentido, a questão essencial, defende Chartier (2002), é o processo pelo qual o leitor dá sentido ao texto. Talvez esteja aqui um "fio solto" nas tramas de Carlos Altamirano e Oscar Terán. Muito embora tangenciada, essa questão não foi melhor explorada, o que Ihes permitiria passear com mais desenvoltura pela internalidade e a externalidade do texto, e mesmo pelos seus elementos mediadores.

Não estaria aqui exatamente uma omissão, mas uma opção. É preciso considerar que as análises de Altamirano e Terán têm também uma historicidade, ligada à história da história intelectual na América Latina. Cumpre pensá-los a partir de um chamado 
"mal-estar", para usar as palavras de Elías Palti (2003, p. 235) acerca da forma que a "história das ideias tradicional" assumiu entre os historiadores latino-americanos. O representante máximo da "velha tradição" e figura chave na instituição da história das ideias como uma disciplina particular no continente na década de 1940, o mexicano Leopoldo Zea, coloriu-a com tons excessivamente ideológicos e dicotômicos. Descrente de que a história dos pensadores latino-americanos pudesse contribuir com uma história das ideias universal, Zea defendeu uma história baseada na relação entre "modelos" e "desvios". Mais do que o "remetente", interessava-Ihe o "destinatário". o objetivo era compreender, no processo de transplantação, as "distorções" em relação às circunstâncias do lugar de recepção e, assim, acessar a história local das ideias (EZCURRA 2010).

Os críticos encontraram sintetizados na proposta de filosofia da história de Zea alguns dos principais problemas não só da história intelectual, mas da historiografia latino-americana de uma maneira geral. Em primeiro lugar, por essa perspectiva insuflar o polêmico princípio de "ideias fora do lugar", a partir da qual se constataria uma assimetria entre Europa e América Latina (PALTI 2006). Como bem demonstrou Maria Sylvia de Carvalho Franco (1976), em interessante debate sobre a obra de Roberto Schwarz, a concepção está intrinsecamente ligada à teoria da dependência e à divisão entre centro e periferia. A ela está subjacente uma interpretação da história das ideias que reduz a linguagem a uma função exclusivamente referencial e uma noção de "cópia local", associada à busca de um "ser nacional", que se resume à luta entre modernidade e tradição, centro e periferia (PALTI 2007).

Contra um possível exotismo das ideias, ergueram-se os adeptos da continuidade, de um ethos passado da cultura hispânica para a latino-americana, encabeçados por Charles Hale. Mas foi com François-Xavier Guerra, a partir da década de 1960, que a crítica à "velha história das ideias" tomou fôlego na América Latina. O revisionismo é parte de uma "transição paradigmática" que abalou a historiografia ocidental 
com um renovado interesse pelos variados elementos da existência humana e a incorporação de novos temas e objetos que colocaram em pauta a multiplicidade de discursos e jogos de linguagem em detrimento das metanarrativas (MALERBA 2009). Influenciado pelos giros linguístico e cultural, Guerra colocou no centro do debate da história político-intelectual latino-americana a questão da linguagem, da sociabilidade, das condições de produção, apropriação e circulação, e do contexto como um aspecto inerente aos discursos (EZCURRA 2010; PALTI 2007).

A renovação historiográfica foi retardada por quase vinte anos na Argentina, graças à ditadura e à repressão generalizada a professores, intelectuais e estudantes. De acordo com Paula Bruno (2010, p. 119-121), foi preciso esperar pelo retorno da vida democrática, em 1983, para o "renascimento" da vida historiográfica na Argentina. Em uma justaposição do contexto nacional com o internacional, o momento coincidiu com o ápice da crise dos paradigmas das ciências sociais que marcou a década de 1970. Emergiram novos projetos, cátedras e programas de pesquisa; historiadores como José Carlos Chiaramonte, Hilda Sabato e Beatriz Sarlo, que nas décadas anteriores seguiram caminhos solitários, ganharam notoriedade. Ainda que sejam vistos como os responsáveis por firmar as bases da "nova história intelectual" argentina, os trabalhos desses autores sofriam a limitação de ainda estarem muito preocupados com as "raízes nacionais" do passado argentino.

O autor desse diagnóstico, publicado em 1990 na revista Espacios de Critica y producción, foi justamente Oscar Terán. Desde pelo menos a segunda metade da década de 1980, Terán havia tomado para si o desafio de pensar a questão nacional argentina, do ponto de vista das "fronteiras móveis da história das ideias", combatendo o risco essencialista. Além de seus trabalhos, os esforços foram concentrados nos debates do Seminario de Historia de las Ideas, los Intelectuales y la Cultura iniciado no Instituto "Dr. Emilio Ravignani", em 1987 (e que continuaram mesmo após a morte de Terán, em 2008). 
Como exaltação a esse clima de fortalecimento da história das ideias na Argentina, nosso segundo autor, Carlos Altamirano, publicou também em 1990, na mesma revista, um ensaio programático, no qual ressaltava a importância de trabalhos recentes, dentre eles o de Terán, e advogava em favor de uma história intelectual livre da influência da "velha" história das ideias, ligada à afirmação da consciência nacional (BRUNO 2010) - como propalada por Zea.

A aproximação maior de nossos dois autores se deu em torno do Programa de Historia y Análisis Cultural, organizado por Terán em 1994 e sob sua direção até 2005, quando passou às mãos de Altamirano e foi por ele conduzido até 2009. Foi também em torno desse programa que se deu o marco da consolidação de espaços, grupos e centros de produção da história intelectual latino-americana: a fundação do periódico Prismas. Revista de historia intelectual, em 1997 (BRUNO 2010, p. 125). Em sua carta editorial de apresentação, a revista colocou-se como resultado de uma demanda premente diante do renovado interesse pelo âmbito teórico internacional da "história das ideias" e das múltiplas abordagens deste objeto de estudo. O plano de ação pautava-se na interdisciplinaridade e na importância atribuída ao "simbólico" pelas ciências sociais. Em essência, fica evidente o diálogo com os objetivos do programa, atualmente convertido em Centro de Historia Intelectual, de estudar o "papel y el trabajo de las representaciones en la vida histórica, incluidas esas representaciones meditadas y teorizadas que son características de las élites culturales".

Compulsando os objetivos do programa com os da revista, é possível estender ao grupo Prismas, ao menos até 2009, os desafios que Bruno (2010, p. 126) pinçou dos ensaios programáticos de Terán e Altamirano na Espacios de Critica: 1) separar a história intelectual da agenda imposta pela busca/consolidação de uma identidade nacional; e 2) ensejar uma história intelectual conectada às variadas contribuições disciplinares e aos debates historiográficos em construção. Em suas Ideias para um Programa de História Intelectual, 
Altamirano (2007, p. 11-13) detalha melhor a proposta. A história intelectual deve privilegiar o discurso, pois são eles que "dão acesso a uma decifração da história", em dois movimentos: "desentranhando" dele o significado oculto, o "encadeamento de sentido que conduz das 'entranhas' da sociedade" de volta à obra. Neste vaivém, os conectores, como procuramos demonstrar, desempenham papel fundamental.

\section{Consideraçōes finais: uma história intelectual à margem?}

A explicação para a identificação da historiografia latinoamericana com as ideias do giro linguístico estaria numa tradição cultural ibero-americana da força da retórica como chave de leitura para a história intelectual (CARVALHO 2000). A questão fulcral, afirma Aguilar Rivera (2008, p. 131), é que o enfoque, há mais de três décadas, em uma história desse tipo trouxe problemas constitutivos, não intencionados. Os historiadores intelectuais da América Latina teriam permanecido à margem da efetiva revolução linguística do mundo anglo-saxão, com uma história dos discursos que tende a apagar o sujeito histórico, a deixar as ideias de lado e a interromper o diálogo com as ideias políticas (EZCURRA 2010). Para nós, Para leer el Facundo e Introducción a Facundo são bons exemplos para questionar a generalidade de tal afirmação, que, em muitos aspectos, segue reproduzindo a máxima de "ideias fora do lugar".

Se o enfoque nos preceitos do giro linguístico pode ser constatado com uma forte - quase inescapável? - tendência da historiografia na América Latina nas décadas de 1980 e 1990, ainda hoje identificável (MALERBA 2009), é preciso não perder de vista que ele não se resume a um essencialismo linguístico como dos anos 1970. A retórica é apenas um dentre muitos componentes. Em linhas gerais, a recente história intelectual latino-americana advém do cruzamento de duas correntes de interpretação. De um lado, a chamada Escola de Cambridge, cujos maiores representantes, Quentin Skinner e John Pocock, determinaram os rumos da história intelectual nos anos 1960 
e 1970, em direção à importância das formas narrativas e das estratégias retóricas (AGUILAR RIVERA 2008). De outro, a Begrisffsgeschichte de Koselleck, segundo a qual o conceito traz uma consciência histórica. A combinação das duas vertentes sintetizaria os aspectos cruciais sobre os quais a "nova" se distinguiria da "velha" história intelectual na América Latina (PALTI 2007).

Ora, Oscar Terán e Carlos Altamirano não passam ao largo do próprio desenrolar dessa história da história intelectual não só argentina e latino-americana, mas ocidental. Mais do que desejado, o debate historiográfico era previsto no programa da Prismas. Nesse sentido, os autores sinalizam percursos que posteriormente desembocaram no que Gabrielle Spiegel (2005) identificou como Practice History. Como explica a autora, o sucesso do giro linguístico entre um número considerável de importantes historiadores foi de tal monta que gerou uma espécie de reação, tanto entre os seus críticos quanto entre os seus seguidores. Uma das respostas foi o deslocamento epistemológico do enfoque das estruturas semióticas dadas para a construção individual e social dos signos; da cultura como discurso para a cultura como prática e performance. Isso trouxe de volta o sujeito histórico, não mais o governado por códigos semióticos impessoais, e sim o agente histórico engajado em flexionar os agentes semióticos.

O ponto de partida de Terán e Altamirano é a história intelectual, mas a preocupação central gravita em torno da ideia de discurso histórico como prática social. A esse respeito, o diálogo que realizam com autores fundamentais da historiografia anglo-saxã e francesa recente, como Darnton, Chartier e Burke, mesmo indiretamente, foi constante, e embasou a escolha de muitos dos mediadores utilizados nas duas análises. Ainda que o espaço não tenha permitido avançar na questão, ensaiamos uma esclarecedora história da recepção dos modelos culturais franco-anglo-saxões na historiografia argentina. Especificamente, de como os conceitos de simbólico e representação, provenientes do giro 
linguístico e cultural, foram operacionais nas análises de Terán e Altamirano, constituindo-se na pedra de toque do programa de história intelectual do grupo Prismas. Se algum senão pode ser sinalizado, é sobre uma possível "dependência cultural" em relação aos cânones produzidos nos países centrais da economia capitalista (MALERBA 2009; REIS 2012), mas essa problemática, dada a sua complexidade, requereria um esforço de análise que foge aos nossos propósitos.

Por ora, importa destacar que os ensaios analisados são altamente significativos do ponto de vista de uma elaboração programática. O Para ler el Facundo parece sintetizar a proposta de Oscar Terán. Cremos não incorrer em equívoco, ao afirmar que o livro de Terán converte-se em uma espécie de laboratório onde aplica as questões debatidas nas páginas da Prismas. Trata-se de ler Facundo com os instrumentos da história intelectual para, assim, pensar a história da Argentina para além da afirmação da consciência nacional, tão cara à "velha" história das ideias. Quanto ao texto de Carlos Altamirano, o próprio fato de escolher o ensaio, cuja primeira versão é de 1993, para incluir em um livro intitulado Para un Programa de Historia intelectual já é autoexplicativo. A análise contém o que ele considera mais significativo em termos de direcionamento teórico-metodológico aos historiadores intelectuais.

No momento em que identificamos as categorias de mediação como um recurso constante de nossos autores, ressaltamos a importância que elas assumem no programa de história intelectual argentina. Oscar Terán e Carlos Altamirano evidenciam com elas a construção de uma ponte de mediação para atuar no espaço de "indeterminação epistemológica" da história intelectual, ou seja, entre a superfície textual dos discursos (ideias) e sua estrutura conceitual mais complexa (PALTI 2007). Para nós, os conectores forneceram os subsídios para escapar das armadilhas de uma história intelectual desencarnada, pautada em uma análise tecnicista do discurso ou, mais precisamente, da historiografia. 


\section{REFERÊNCIAS BIBLIOGRÁFICAS}

AGUILAR RIVERA, José Antonio. El tiempo de la teoría: la fuga hacia los lenguajes políticos. A Contracorriente, [S.I.], v. 6 , n. 1, p. 179-188, 2008. Disponível em: <https://goo.gl/ eVD8fx>. Acesso em: 28 set. 2017.

ALTAMIRANO, Carlos. Introducción al Facundo. In: Para un Programa de Historia Intelectual y otros Ensayos. Buenos Aires: Siglo XXI, 2005, p. 25-61.

- Ideias para um Programa de História Intelectual. Tempo Social. Revista de Sociologia da USP, v. 19, n. 1, p. 09-17, 2007. Disponível em: https://goo.gl/CvNjui. Acesso em: 28 set. 2017.

BEIRED, José Luis Bendicho. Tocqueville, Sarmiento e Alberdi: três visões sobre a democracia nas Américas. História, São Paulo, v. 22, n. 2, p. 59-78, 2003. Disponível em: https:// goo.gl/DFXpSU. Acesso em: 28 set. 2017.

BRUNO, Paula. Notas sobre la historia intelectual argentina entre 1983 y la actualidad. Cercles, Revista d'Història Cultural, v. 13, 2010, p. 113-133. Disponível em: https://goo.gl/ GB3WMU. Acesso em: 28 set. 2017.

BURKE, Peter. La historia intelectual en la era del giro cultural. Prismas. Revista de Historia Intelectual, v. 11, n. 2, p. 159-164, 2007. Disponível em: https://goo.gl/ZgqwMw. Acesso em: 28 set. 2017.

CARVALHO, José Murilo de. História intelectual no Brasil: a retórica como chave de leitura. Topoi, Rio de Janeiro, v. 1, n. 1, p. 123-152, 2000. Disponível em: https://goo.gl/vSt4UA. Acesso em: 28 set. 2017.

CARVALHO FRANCO, Maria Sylvia de. As ideias estão em seu lugar. Cadernos de Debate, no 1, p. 61-64, 1976. 
CERTEAU, Michel. A Escrita da História. São Paulo: Forense Universitária, 2008.

CHARTIER, Roger. À Beira da Falésia: a história entre certezas e inquietudes. Porto Alegre: Ed. Universidade/UFRGS, 2002.

\section{Literatura e Cultura Escrita: estabilidade} das obras, mobilidade dos textos, pluralidade das leituras. Conferência proferida no II Colóquio Internacional de Estudos Linguísticos e Literários (Cielli), realizado na Universidade Estadual de Maringá, Paraná/Brasil, de 13 a 15 de junho de 2012.

COMPAGNON, Antoine. O Trabalho da Citação. Belo Horizonte: Ed. UFMG, 1996.

DARNTON, Robert. ¿Qué es la historia del libro?. Prismas. Bernal, v. 12 , n. 2, p. $135-155,2008$. Disponível em: https://goo.gl/EFh9ps. Acesso em: 28 set. 2017.

DOSSE, François. De I'histoire des idées à I'histoire intellectuelle. In: LEYMARIE, Michel; SIRINELLI, Jean-François (dirs. ). L'Histoire des Intellectuels Aujourd'hui. Paris: PUF, 2003, p. 161-182.

EZCURRA, Mara Polgovsky. La historia intelectual latinoamericana en la era del "giro lingüístico". Nuevo Mundo Mundos Nuevos, 2010. Disponível em: https://goo.gl/ Dd6YgT. Acesso em: 28 set. 2017.

FOUCAULT, Michel. O que é um Autor? Lisboa: Editora Passagens, 1992.

GENETTE, Gérard. Paratexts: thresholds of interpretation. Cambridge University Press: 1997.

GOLDMAN, Noemí; PASINO, Alejandra. Opinión Pública. In: GOLDMAN, Noemi (Ed.). Lenguaje y Revolución: conceptos políticos clave en el Rio de la Plata, 1780-1850. Buenos Aires: 
Prometeo, 2008, p. 99-113.

HALPERIN DONGHI, Tulio. Historia Argentina: de la revolución de independencia a la confederación rosista. $4^{a}$ reimpressão. Buenos Aires: Editorial Paidós, 1993.

KOSELLECK, Reinhart. Futuro passado. Contribuições à semântica dos tempos históricos. Rio de Janeiro: Contraponto; Ed. PUC-Rio, 2006.

LACAPRA, Dominick. Rethinking Intellectual History and Reading Texts. History and Theory, v. 19, n. 3, p. 245-276, 1980. Disponível em: https://goo.gl/Bpfkta. Acesso em: 28 set. 2017.

MALERBA, Jurandir. A História na América Latina: ensaio de crítica historiográfica. Rio de Janeiro: Ed. FGV, 2009.

PALTI, Elías. La Historia Intelectual Latinoamericana y el malestar de nuestro tempo. Anuario IEHS, n. 18, p. 233-249, 2003. Disponível em: https://goo.gl/5gu9mf. Acesso em: 28 set. 2017.

- La Nueva Historia Intelectual y sus repercusiones en América Latina. História Unisinos, v. 11, n. 3, p. 297-305, 2007. Disponível em: https://goo.gl/NhNEqo. Acesso em: 28 set. 2017.

The Problem of 'Misplaced Ideas' Revisited: Beyond the 'History of Ideas' in Latin America. Journal of the History of Ideas, n. 1 , p. 149-179, 2006. Disponível em: http://www.jstor.org/stable/3840404 28 set. 2017.

PONTES, Heloísa. Círculos de intelectuais e experiência social. Revista Brasileira de Ciências Sociais, v. 12, n. 34, p. 57-69, 1997.

PRADO, Maria Ligia Coelho. A América Latina no Século XIX: tramas, telas e textos. São Paulo: Editora da Universidade de São Paulo, 2004. 
REIS, José Carlos. Teoria \& História: tempo histórico, história do pensamento histórico ocidental e pensamento brasileiro. Rio de Janeiro: Editora FGV, 2012.

RICOEUR, Paul. Tempo e Narrativa. Tomo I. Campinas: Editora Papirus, 1994.

RÜSEN, Jörn. Razão Histórica - Teoria da História: os fundamentos da ciência histórica Brasília: Editora UnB, 2001.

SCHORSKE, Carl E. Vienna Fin-de-Siècle. Política e Cultura. Campinas/São Paulo, Editora da Unicamp/Companhia das Letras, 1998.

SIRINELLI, Jean-François. Os Intelectuais. In: REMOND, René (org.). Por uma História Política. Rio de Janeiro: FGV, 2003, p. 231-269.

SKINNER, Quentin. Meaning and Understanding in the History of Ideas. History and Theory, v. 8, no 3, 1969 , p. 3-53.

SPIEGEL, Gabrielle (Ed.). Introduction. In: Practicing History: new directions in historical writing after the linguistic turn. London: Routledge, 2005.

TÉRAN, Oscar. Para Leer el Facundo. Civilización y barbarie: cultura de fricción. Buenos. Aires: Capital Intelectual, 2007.

WASSERMAN, Fábio. Entre Clio y La Polis: conocimiento histórico y representaciones del pasado en el Río de La Plata (1830-1860). Buenos Aires: Editorial Teseo, 2008.

\section{AGRADECIMENTOS E INFORMAÇŌES}

\section{Fabiula Sevilha}

fsevilhas@yahoo.com.br

Doutora em História

Universidade Federal de Minas Gerais

Avenida Monteiro da Franca, 661 - Apto 1302 - Manaíra

58038-320 - J oão Pessoa - Paraíba

Brasil 
Agradeço à Profa. Eliana Dutra (UFMG) pelo estímulo à muitas das reflexões aqui apresentadas a partir de conversas, aulas e dos debates no grupo de estudos Brasiliana. Agradeço também à CAPES (PROEX) a bolsa usufruída no período em que esta pesquisa foi realizada.

RECEBIDO EM: 01/10/2017 |APROVADO EM: 13/04/2018 